\title{
Magnetic Separation Nanotechnology for Spent Nuclear Fuel Recycle
}

Leigh R. Martin, Y. Qiang, YQ. Wu

October 2014

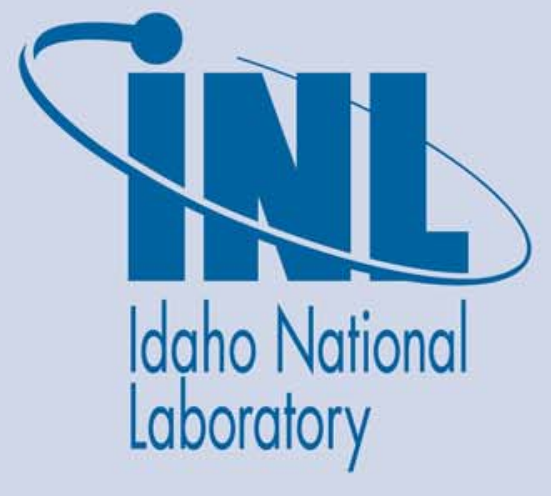

The INL is a U.S. Department of Energy National Laboratory operated by Battelle Energy Alliance 
INL/EXT-14-33409

\title{
Magnetic Separation Nanotechnology for Spent Nuclear Fuel Recycle
}

\author{
Leigh R. Martin, Y. Qiang, YQ. Wu
}

October 2014

\author{
Idaho National Laboratory \\ Idaho Falls, Idaho 83415
}

http://www.inl.gov

Prepared for the

U.S. Department of Energy

Office of Nuclear Energy

Under DOE Idaho Operations Office

Contract DE-AC07-05ID14517 
Title: Magnetic Separation Nanotechnology for Spent Nuclear Fuel Recycle Principal Investigators: Leigh R. Martin (INL), Y. Qiang (UI) and YQ. Wu (BSU)

\section{Part 1: Study on sorption-stripping cycles}

The ability to reuse the dMNP-DPTA conjugates were investigated by performing up to 15 cycles of sorption/desorption tests. Three-step-washing stripping process using either $0.1 \mathrm{M} \mathrm{HNO}_{3}$ or 1 $\mathrm{M} \mathrm{HCl}$ as the stripping agent was developed. As shown in Figure 1, for both cases, over $98 \%$ of $\mathrm{Cd}$ was recovered by the first two acid stripping steps, and there was a negligible amount of $\mathrm{Cd}$ in the third time deionized water washing. No decrease in sorption efficiency was observed during 15 sorption/desorption cycles.
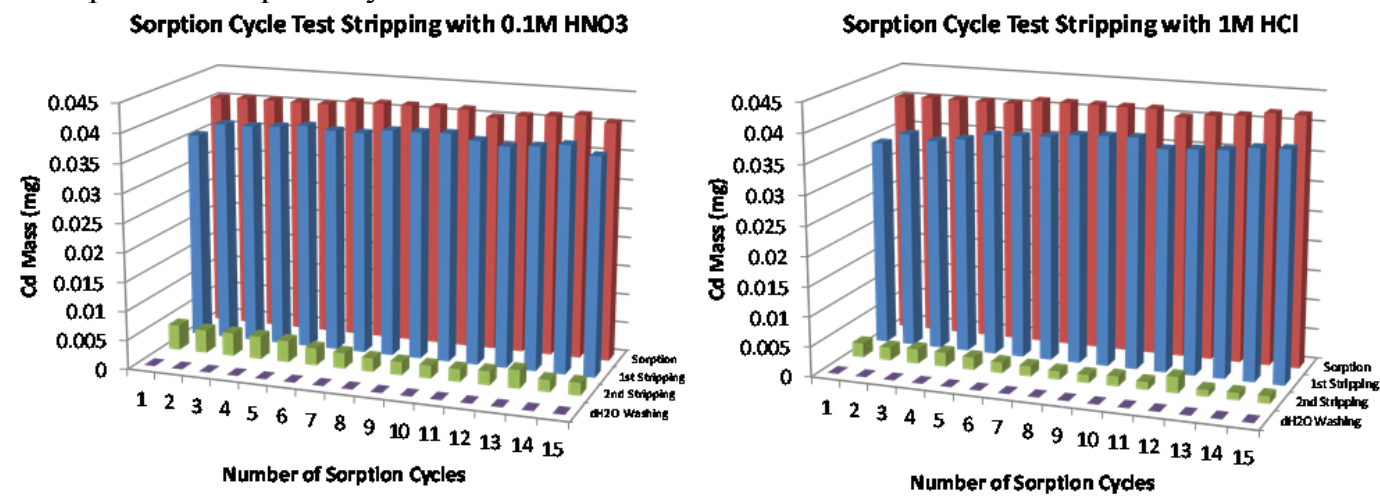

Figure 1. Mass of extracted and back-extracted Cd during 15 sorption/stripping cycles with dMNP-DTPA conjugates.

\section{Part 2: Study on technetium (Tc) sorption}

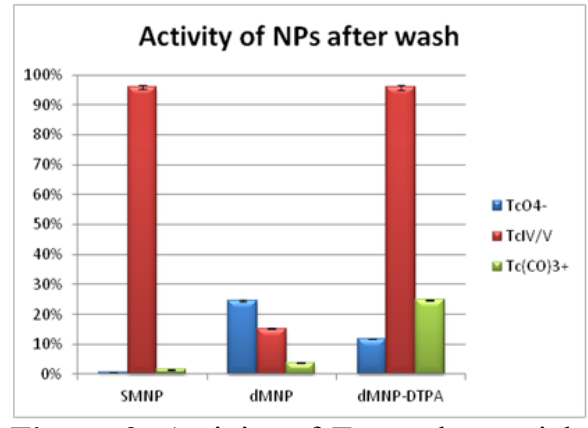

Figure 2. Activity of Tc on the particles (sMNP, dMNP, and dMNP-DTPA) after 1 hour of sorption contact time.
Preliminary technetium (Tc) sorption study was performed using trace leval of $\mathrm{TcO}^{4-}, \mathrm{Tc}(\mathrm{IV} / \mathrm{V})$, and $\mathrm{Tc}(\mathrm{CO})^{3+}$ in aqueous solution. As shown in Figure 2, $\mathrm{Tc}(\mathrm{IV} / \mathrm{V})$ is the most reactive species with either sMNP or dMNP-DTPA conjugates with over $95 \%$ removal efficiency. For $\mathrm{TcO}^{4-}$ and $\mathrm{Tc}(\mathrm{CO})^{3+}$ sorption, although the sorption efficiency was not as high as $\mathrm{Tc}(\mathrm{IV} / \mathrm{V})$, positive sorption was observed. The sorption efficiency could be improved by adjusting the reaction conditions.

\section{Part 3: Study on trivalent lanthanide (Ln(III)) sorption}

Sorption experiments on dMNP-DTPA conjugates were conducted for $\mathrm{Ln}(\mathrm{III})$ series solution (La-Ho, except Pm). Sorption kinetics and $\mathrm{pH}$ effect were evaluated. Ln(III) sorption equilibrium was reached after 30 min of contact time. The sorption efficiency increased with the increasing the atomic number, which was due to the lanthanide contraction wherein the ionic radii of the $\mathrm{Ln}(\mathrm{III})$ decrease with an increase in the atomic number.

Part 4: Study on trivalent americium (Am(III)) and trivalent europium (Eu(III)) separation Sorption experiments on dMNP-DTPA conjugates were conducted for Ln(III) series solution (LaHo, except Pm) spiked with trivalent Am-243 and trivalent Eu-154. Freshly made dMNP-DTPA (New) and dMNP-DTPA after 6 months of storage (Old) were used to evaluate the sample degradation. After 2 hours of contact time, the $K_{\mathrm{d}}$ value was $2700 \mathrm{~mL} / \mathrm{g}$ for Am-254 and 2000 $\mathrm{mL} / \mathrm{g}$ for Eu-154 in $\mathrm{pH} 3.0$ buffer. At $\mathrm{pH}$ 1.0, there was no sorption on dMNP-DTPA conjugates for both cases. The separation radio of $\mathrm{Eu}(\mathrm{III}) / \mathrm{Am}$ (III) was only $\sim 0.7$. Future study is needed to increase the separation radio. 


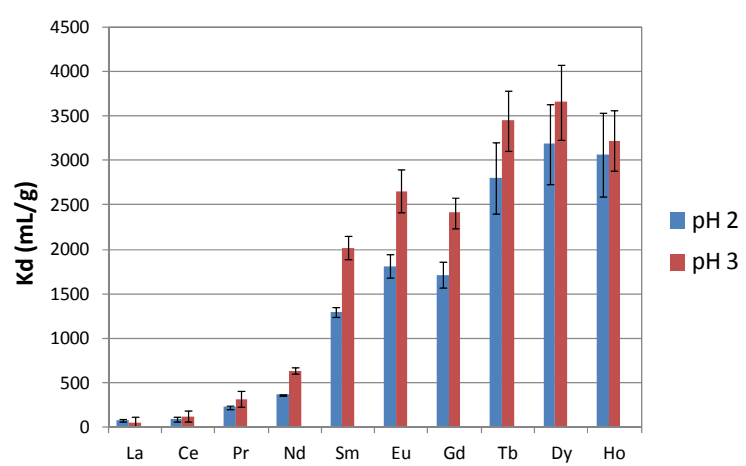

Figure 3. Effects of $\mathrm{pH}$ and atomic number on the sorption efficiency (after 2 hour of contact time).

irradiation as well as phase change. These coreshell nanoparticle granular films continued to remain ferromagnetic with core unaffected even after irradiation. The grain size of the $\mathrm{Fe}(\sim 8 \mathrm{~nm})$ core remained unchanged, with only the growth of shell size from $2 \mathrm{~nm}$ to $17 \mathrm{~nm}$. The oxide shell of these nanoparticles had stoichiometry change from $\mathrm{Fe}_{3} \mathrm{O}_{4}$ to $\mathrm{FeO}$ under irradiation and the new $\mathrm{Fe}-\mathrm{FeO}$ interface played a vital role in protecting the core. It has also been found that valence reduction of Iron oxides happen only if pure nanocrystalline $\mathrm{Fe}$ is present; otherwise no reduction behavior was observed. This research finding contributes to enhancing the stability of materials through stoichiometry and nanomaterials synthesis.

\section{Part 5: Stability of magnetic nanoparticles under Irradiation.}

Under the project, a portion of research was focused on investigating the irradiationinduced modification in nanomaterials through the understanding of stability and sensitivity of nanomaterials under irradiation. Our investigation of $\mathrm{Si}^{2+}$ ionirradiation (5.5 MeV to fluence of 1016 ions $/ \mathrm{cm} 2$ ) on core-shell iron-iron oxide nanoparticle granular films has brought forth some interesting results resisting

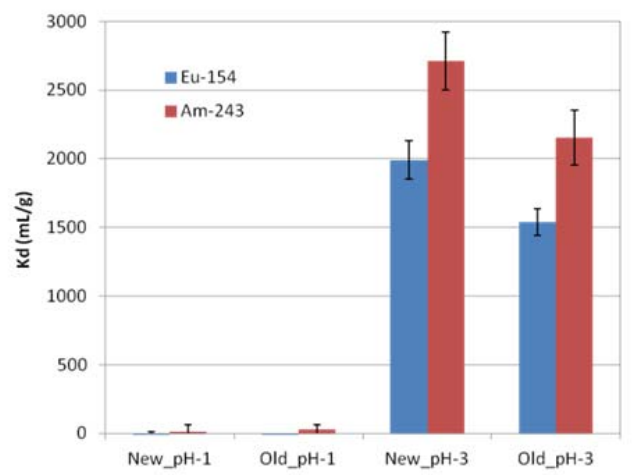

Figure 4. Sorption efficiency of $\mathrm{Am}(\mathrm{III})$ and $\mathrm{Eu}(\mathrm{III})$ on new and old dMNP-DTPA conjugates under $\mathrm{pH}$ 1.0 and $\mathrm{pH} 3.0$ (after 2 hour of contact time).

\section{Part 7: TEM Characterization of MNPs.}

Nano-sized magnetic powder samples coded MNP, sMNP, dMNP, dMNP-DTPA and dMNPDTPA-Ln were characterized by using transmission electron microscopy (TEM) technique. Figure 5 shows representative microstructures of the samples. In addition, their chemical compositions were confirmed by using energy dispersive X-ray spectroscopy (EDS) technique. The TEM images clearly show that the successive increase in thickness of coating on MNPs by different surface functionalities. The thickness of the first silica coating is $\sim 40 \mathrm{~nm}$ (Fig. 5b). After second coating, the size of particles with polymer structure (silica and polyamine) significantly increased to micro-scale (Fig. 5c). The first silica coating was still clearly recognizable after the second coating (Fig. 5d). The DTPA attachment did not have a significant effect on the particle size and surface structure (Figs. 5e and 5f). The TEM images also revealed that the first silica coating was not coated on the individual iron/iron oxide MNPs. Instead, the MNPs agglomerated before the surface coating. Another issue with the conventional TEM analysis is that it requires dry samples. However, the size and surface structure of dMNP and dMNP-DTPA particles significantly changed after dry due to the water-absorbing polymer structure of polyallylamine on the second coating. Therefore, other imaging technique will be needed which allows doing the sample analysis in aqueous solution.

\section{Part 8: AFM/MFM characterization of MNPs}

Atomic force microscopy and magnetic force microscopy were employed to characterize coreshell $\mathrm{Fe}-\mathrm{Fe}$ oxide $5 \mu \mathrm{m}, \mathrm{Fe}$-oxide $5 \mu \mathrm{m}$ and Fe-oxide $40 \mu \mathrm{m}$ magnetic nano-sized powder samples. The AFM images give surface morphology of the $5 \mu \mathrm{m}$ MNPs (Figs. 6a, 6b). In the AFM images, the brighter contrast means higher height of the particles. For example, the 
brightest (white color) contrast represents a height over $400 \mathrm{~nm}$. MFM is useful to show magnetic domains in the sample.

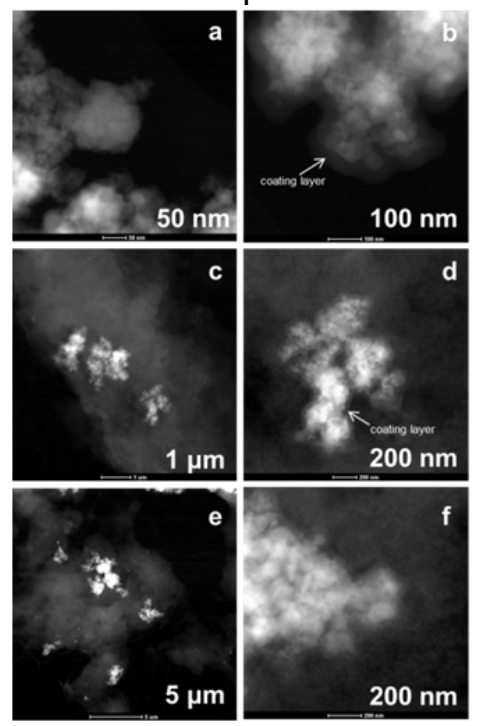

Figure 5. TEM images of MNPs before and after surface functionalization with silica, co-precipitation of silica and polyallylamine, and complex conjugate of DTPA attached MNPs. (a) Uncoated MNP, (b) sMNP, (c) dMNP, and (d) dMNP-DTPA.

The boundaries between bright and darker contrast areas in the MFM images of Fe-oxide samples (Figs. 6b and 6c) should represent the magnetic domain boundaries in the two samples.
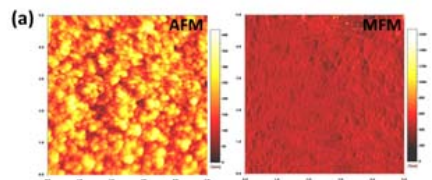

(b)

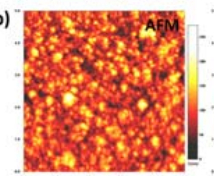

(c)
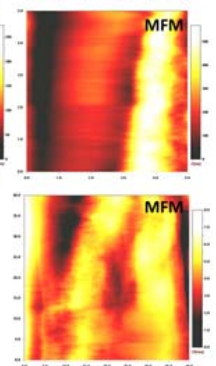

Figure 6. AFM and MFM characterization of MNPs. (a) core-shell Fe-Fe oxide $5 \mu \mathrm{m}$, (b) Fe-oxide $5 \mu \mathrm{m}$ and (c) Feoxide $40 \mu \mathrm{m}$.

\section{Part 9: Future study plan}

The Tc sorption efficiency will be improved by adjusting the reaction conditions, such as changing the $\mathrm{pH}$, increase the amount of particles, or conducting the tests at macro scale, etc. The separation radio of $\mathrm{Eu} / \mathrm{Am}$ will be improved either by oxidizing $\mathrm{Am}(\mathrm{III})$ to a higher oxidation states $(\mathrm{Am}(\mathrm{V} / \mathrm{VI})$ ) to reduce the complexing reaction between Am and DTPA, or by conjugating a kind of new metal chelator that has a high sorption selectivity to Ln(III) over trivalent actinide (An(III)), such as Di-(2-ethylhexyl)phosphoric acid (HDEHP), to the surface functionalized MNPs. Magnetic separator design for the continuous operation will be continued.

\section{Journal Publications:}

1. Kaur, M.; Zhang, H.; Qiang, Y., "Magnetic Separation Dynamics of Colloidal Magnetic Nanoparticles," Magnetics Letters, IEEE, vol.4, no., pp.4000204, 2013.

2. M. Kaur, Y. Qiang et al, "Separation nanotechnology of diethylenetriamine-pentaacetic acid bonded magnetic nanoparticles for spent nuclear fuel," Nano Energy, 2013, vol. 2, no. 1, pp. 124-132

3. Kaur, M.; Zhang, H.; Martin, L.; Todd, T.; Qiang, Y., "Conjugates of Magnetic Nanoparticle Actinide Specific Chelator for Radioactive Waste Separation". Environmental Science \& Technology, 2013, 47 (21), 11942-11959.

4. Qiang, Y., Kaur, M.; Zhang, H.; Martin, L.; Todd, T., "Magnetic Separation - advanced nanotechnology for future nuclear fuel recycle". ANS Global 2013. MS \# 7597.

5. Zhang, H.; Kaur, M.; Qiang, Y., "Magnetic Nanosorbents for Fast Separation of Radioactive Waste". ANS Global 2013. MS \# 7602.

6. J.A. Sundararajan, M. Kaur, W. Jiang, J. S. McCloy, and Y. Qiang, Oxide shell reduction and magnetic property changes in core-shell Fe nanoclusters under ion irradiation, Journal of Applied Physics, 115, 17B507, 2014

7. J.S. McCloy, W. Jiang, T.C. Droubay, T. Varga, E.C. Burks, J. A. Sundararajan, M. Kaur, Y. Qiang, L. Kovarik, K. Liu, Ion irradiation of Fe-Fe oxide core-shell nanocluster films: Effect of interface on stability of magnetic properties, Journal of Applied Physics, 114, 083903, 2013.

Conference presentations:

1. Maninder Kaur, Yaqiao Wu, Huijin Zhang, Leigh Martin, Terry Todd and You Qiang, "Nanoparticle for Used Nuclear Fuel Separation", TMS 2014, San Diego, Feb. 16-20, 2014. 
2. Y. Q. Wu, M. Kaur, H. Zhang, Y. Qiang, L. R. Martin, Terry Todd, "Magnetic Cr-doped Fe-Fe oxide core-shell nanoparticles for used nuclear fuel separation", TMS 2015, accepted. 